\title{
Efeitos da Construção de um Jogo Educativo de Matemática nas Atitudes e Aprendizagem Alunos: Estudo de Caso
}

\author{
Effects of the Construction of an Educational Mathematics \\ Game on Students' Attitudes and Learning: Case Study
}

Paula Sofia Nunes *
Armando A. Soares
Paula Catarino

Universidade de Trás-os-Montes e Alto Douro, Portugal

\begin{abstract}
Este trabalho descreve o processo de conceção e desenvolvimento de um jogo educativo de matemática denominado "Trivial matemático", por alunos do $8 .{ }^{\circ}$ ano de escolaridade, numa escola pública de Portugal, O jogo possibilita exercitar os mais variados conteúdos de matemática, através de pequenas adaptações, em qualquer ano de escolaridade do ensino básico. Neste trabalho investigou-se se a conceção de um jogo educativo promove a aprendizagem de conceitos matemáticos e identificaramse implicações nas atitudes dos alunos face à matemática. A metodologia utilizada foi um design de estudo de caso. Trata-se de um estudo de caso misto pelo facto de existir uma combinação de instrumentos e técnicas, associadas aos estudos qualitativos e quantitativos. A recolha de dados, foi feita através da observação naturalista, da aplicação de tarefas e da aplicação de um inquérito por questionário. Na análise estatística dos dados foi utilizado o software SPSS. Os resultados obtidos sugerem que a utilização do jogo educativo, como recurso de apoio às aulas, produz uma melhoria significativa das atitudes dos alunos face à matemática, bem como, contribui para desenvolver a motivação dos alunos. Além disso, o processo de construção do jogo educativo aponta para uma melhoria na aprendizagem de conceitos geométricos inerentes ao jogo.
\end{abstract}

Palavras-chave: Matemática; Aprendizagem; Jogos educativo; Atitudes; Motivação.

This work describes the process of conception and development of an educational game of mathematics called "Mathematical Trivial", by students of the eighth grade of schooling, in a public school in Portugal. The game allows to practice the most varied mathematical contents through small adaptations, in any year of elementary education. In this work, we investigated whether the design of an educational game promotes the learning of mathematical concepts and identified the implications of students' attitudes towards mathematics. The methodology used was a case study design. This is a mixed case study because there is a combination of tools and techniques associated with qualitative and quantitative studies. The data collection was done through naturalistic observation, the application of tasks and the application of a questionnaire survey. Statistical analysis of the data was performed using SPSS software. The results suggest that the use of the educational game, as a resource to support the classes, produces a significant improvement of the students 'attitudes towards mathematics, as well as, it contributes to develop students' motivation. In addition, the process of constructing the educational game points to an improvement in the learning of geometrical concepts inherent to the game, in a playful and dynamic way.

Keywords: Mathematics; Learning; Educational games; Attitudes; Motivation.

*Contacto: psofianunes1@gmail.com

ISSN: 1696-4713

www.rinace.net/reice/

revistas.uam.es/reice
Recibido: $\quad 5$ de junio 2018

$1^{\text {a }}$ Evaluación: 13 de julio 2018

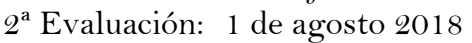

Aceptado: $\quad 20$ de agosto 2018 


\section{Introdução}

Desde há muito tempo que se tem vindo a pesquisar sobre várias formas de tornar os processos de ensino e de aprendizagem mais satisfatórios para alunos e professores (Silva e Morais, 2011). Apesar de existir um senso comum entre educadores de que é necessário mudar o tradicionalismo que privilegia a replicação de conhecimentos já estabelecidos, na maioria das instituições de ensino prevalecem aulas tradicionais, com recurso a práticas de ensino centradas no professor, emissor de todo o conhecimento, que os alunos, de forma disciplinada devem absorver (Victal et al., 2015).

A matemática é uma disciplina que lida com conceitos muito abstratos, que por vezes são difíceis de entender pelos alunos. Uma das formas de minimizar este problema, prende-se com o uso de jogos didáticos que apelem à utilização de várias ferramentas que contribuem para a concretização de conceitos abstratos de matemática. Nesta investigação, pretendese criar uma ferramenta/jogo educativo e verificar o impacto da construção deste artefacto, pelos alunos, na melhoria das aprendizagens e das atitudes face à matemática.

A razão pela qual escolhemos este tema para investigar, prende-se com a necessidade de fazer algo mais pelos alunos com dificuldades de aprendizagem e com insucesso à disciplina de matemática bem como estimular a criatividade dos alunos. O desinteresse de alguns alunos pelo ensino em sala de aula e as dificuldades que enfrentam em relação à matemática, são razões mais do que suficientes para que os professores encontrem novas estratégias nas suas práticas de ensino, para ajudar a superar as dificuldades e obstáculos sentidos por muitos alunos a esta disciplina. Resultados oficiais de Baptista e DGEECDireção Geral de Estatísticas da Educação e Ciência (2017, 2018), identificam a matemática como sendo uma das disciplinas com maior insucesso no ensino básico e no ensino secundário, um problema que persiste ao longo dos sucessivos anos e que ainda não se encontraram métodos/estratégias satisfatórios para minimizar este problema do ensino da matemática.

Em termos gerais, várias investigações produzidas são favoráveis à utilização de jogos educativos no ensino da matemática. O principal objetivo da utilização dos jogos fundamenta-se na melhoria da aprendizagem de cada aluno. De acordo com o quadro teórico disponível, os jogos poderão motivar os alunos, ajudar a estruturar e consolidar conhecimentos adquiridos ou mesmo levá-los a descobrir novos conceitos (Gonçalves, 2011).

Na tentativa de colmatar dificuldades de se ensinar alguns conteúdos abstratos, relacionados com a disciplina de matemática, e com a preocupação de desenvolver metodologias e estratégias alternativas de ensino para os alunos, levámos a cabo a presente investigação. Pretende-se estudar, num grupo restrito de alunos, se a construção de jogos educativos, pelos discentes, ajuda a promover atitudes mais positivas em relação à matemática e se esta metodologia de ensino poderá contribuir para uma melhor aprendizagem de conceitos de matemática, implícitos na construção do jogo.

Neste trabalho procuramos responder às seguintes questões de investigação: i) será que a participação no design da construção de jogos didáticos contribui para aumentar a motivação na aprendizagem de matemática? e ii) os processos de conceção e desenvolvimento de jogos didáticos fomentam o pensamento matemático e contribuem para melhorar a aprendizagem de matemática? 
Este estudo tem os seguintes objetivos:

- Construir jogos educativos, que utilizem materiais manipuláveis e verificar que impacto têm na motivação dos alunos na disciplina de matemática.

- Averiguar se a participação na construção de jogos didáticos de matemática contribui para a melhoria das na aprendizagem dos alunos.

- Tirar partido dos jogos educativos para melhorar as aprendizagens em matemática.

O presente artigo encontra-se estruturado da seguinte forma: a próxima secção diz respeito à fundamentação teórica do papel da construção e utilização de jogos educativos na aprendizagem de matemática. De seguida, apresenta-se o método adotado nesta investigação, com a descrição das características do jogo construído com os alunos, denominado “Trivial matemático", a caracterização dos participantes, e a descrição dos instrumentos de recolha de dados. Seguem-se a análise e discussão dos resultados e finalmente, expomos as conclusões e considerações finais, procurando relacionar a perspetiva teórica com os resultados obtidos no estudo empírico.

\section{Fundamentação teórica}

\subsection{O papel dos jogos educativos na aprendizagem de matemática}

Jogos, paradoxos e puzzles sempre estiveram presentes ao longo de toda a história da matemática, originando um fenómeno regular ao longo dos tempos e nos mais variados locais. Alguns jogos começaram por ser situações problemáticas envolvendo números e formas geométricas que criavam padrões ou regularidades, que permitiram estudos aprofundados, conduzindo ao desenvolvimento do próprio jogo e à descoberta de novas propriedades matemáticas (Moreira e Oliveira, 2004, p.70).

Segundo Godoy e Menegazzi (2014), a utilização de jogos no ensino da matemática surgiu da necessidade do professor procurar alternativas que aumentassem a motivação para a aprendizagem do aluno, explorando a concentração, o raciocínio lógico e a aprendizagem cooperativa. O uso destas ferramentas educativas representa, uma mudança da postura do professor no ensino da matemática, isto é, o papel do professor muda de transmissor de conhecimentos, para observador, mediador, consultor e incentivador da aprendizagem.

Um jogo educativo tem como principal objetivo promover o equilíbrio entre duas funções: a função lúdica e a função educativa. Além disso, um jogo educativo apresenta dois sentidos: o amplo e o restrito. O primeiro visa o desenvolvimento geral da criança, através da exploração livre; o segundo visa a aquisição de conteúdos específicos e de habilidades intelectuais (Zeza et al., 2012). Os Grübel e Bez (2006) referem que os jogos educativos podem ser um excelente recurso didático ou estratégia de ensino para os educadores e serem um rico instrumento para a construção do conhecimento, porque podem facilitar os processos de ensino e de aprendizagem e serem simultaneamente prazerosos, interessantes e desafiantes. Kishimoto (1994) menciona que o jogo é muito importante para o desenvolvimento da criança pois promove a descentração, a aquisição de regras, a expressão do imaginário e a apropriação de conhecimento. $\mathrm{O}$ autor refere ainda que o jogo tem uma forte finalidade educativa pois estimula a exploração e resolução de problemas, e cria ambientes propícios ao desenvolvimento de investigações e procura de soluções. 
De acordo com Moratori (2003), o jogo pode ser considerado um importante meio educacional, pois contribui para o desenvolvimento integral das várias áreas cognitiva, afetiva, linguística, social, moral e motora. Para além disso, contribui para o desenvolvimento da autonomia, criatividade, criticidade, responsabilidade e cooperação entre crianças e jovens.

Ke e Grabowski (2007) estudaram os efeitos da utilização de jogos educativos sobre o desempenho e atitudes em relação à matemática. Para esse efeito, testaram conhecimentos matemáticos em três grupos diferentes: grupo sem jogos, grupo a jogar de forma competitiva e outro a jogar de forma cooperativa. Concluíram que a utilização de jogos educativos no grupo do jogo cooperativo promoveu resultados de aprendizagem cognitivos e afetivos. O jogo cooperativo apenas favoreceu a aprendizagem cognitiva. Ambas as formas de jogar, apresentaram resultados superiores, em todas as dimensões testadas, comparados com o grupo de controlo. Pelo exposto, os autores concluíram que a utilização de jogos educativos e da aprendizagem cooperativa poderiam ser usados em simultâneo para enriquecer a educação matemática.

McLaren e outros (2017) dedicaram-se a investigar quais os benefícios em aprender matemática a partir de jogos educacionais, comparando com uma abordagem de ensino mais convencional. Com esse propósito, utilizaram no seu estudo dois grupos distintos: o grupo experimental realizou as tarefas no computador, recorrendo a um jogo educativo; $\mathrm{o}$ grupo de controlo realizou as mesmas tarefas no computador, mas sem recorrer ao jogo. De uma forma sucinta, concluiu que o grupo que utilizou o jogo na realização das tarefas teve um maior desempenho, manifestou maior motivação e efetuou menos erros do que o grupo sem jogos. Concluiu também que o grupo do jogo não levou mais tempo a concluir as tarefas e que os alunos que apresentaram o menor conhecimento prévio no pré-teste foram os que beneficiaram mais do jogo. Pelo exposto, McLaren e outros (2017) concluíram que a utilização de um jogo educativo promoveu um desempenho superior, em comparação com o desempenho do grupo que realizou, numa abordagem de ensino mais convencional, as tarefas.

A ideia central da investigação aqui exposta, baseia-se no facto da matemática lidar com conceitos abstratos, que por vezes são difíceis de entender pelos alunos. A utilização dos jogos matemáticos no ensino pode de alguma maneira facilitar as aprendizagens uma vez que os conceitos são apresentados de uma forma mais concreta. Assim, a utilização de jogos como recurso educativo veio, de certa forma, mudar a metodologia do ensino tradicional, onde se privilegiava a replicação de conhecimentos já estabelecidos, com recurso a práticas de ensino centradas no professor. Assim, o uso de jogos educativos representa uma mudança do papel e da postura do professor no ensino da matemática.

Em termos gerais, várias investigações produzidas são favoráveis à utilização de jogos educativos no ensino da matemática. No entanto, ainda são escassas as investigações acerca dos benefícios em aprender matemática a partir de jogos educativos, em oposição a abordagens de ensino mais tradicionais (McLaren et al., 2017).

\subsection{Aprendizagem na construção de um jogo didático de matemática}

Silva (2015) refere que, apesar de vivermos numa época de grandes avanços tecnológicos, torna-se evidente que o insucesso na matemática, se prende com o facto de o seu programa oficial continuar com propostas pedagógicas desajustadas dos atuais interesses dos alunos, que não os motivam para a verdadeira compreensão desta disciplina. Silva (2015) propõe, 
para corrigir deficiências na área da matemática, uma didática relacionada com a utilização do lúdico, onde os alunos utilizem o raciocínio lógico, a capacidade para observar e analisar criticamente caminhos para a resolução de problemas. Trazer o espírito lúdico para a sala de aula proporciona um envolvimento dos alunos no seu próprio conhecimento, provocando o desenvolvimento de competências para questionar e analisar a informação adquirida.

Vários estudos indicam os efeitos positivos no processo de criação e da utilização de jogos educativos na aprendizagem e nas atitudes em relação à disciplina de matemática. Ke (2014) investigou o potencial da criação de jogos de computador na aprendizagem da disciplina de matemática. Concluiu que o envolvimento dos alunos na criação do design de um jogo educativo, desenvolveu o pensamento matemático, promoveu atitudes mais positivas em relação à disciplina e desafiou-os a executar tarefas que contribuíram para o desenvolvimento do raciocínio abstrato.

No mesmo sentido, Katmada, Mayridis e Tsiatsos (2014) desenvolveram e aplicaram um jogo educativo para auxiliar os educadores no ensino da matemática. O protótipo do jogo foi avaliado através de um estudo piloto numa intervenção a longo prazo, em contextos escolares reais, para avaliar aspetos de usabilidade e possíveis falhas. As opiniões recolhidas dos alunos foram positivas e consideraram que era uma ferramenta de aprendizagem útil e envolvente, independentemente da idade ou do género. Neste estudo concluíram que o jogo educativo promoveu a aprendizagem e as atitudes em relação à matemática, pelo que poderá ser utilizado pelos professores, como um recurso útil de apoio ao currículo formal.

Shimohara e Sobreira (2015) desenvolveram um trabalho que compreendeu a criação de jogos digitais pelos alunos, com desafios de matemática, aliando o poder motivador dos jogos, à criação de desafios. Concluíram que os alunos desenvolveram a autonomia na programação do jogo ao longo do projeto, desenvolveram habilidades de autoria e protagonismo. Este projeto contribuiu para promover o desenvolvimento de conceitos matemáticos, da capacidade de resolução de problemas e estimulou a (re)formulação de problemas de forma significativa.

Também Silva e Morais (2011) se debruçaram sobre a influência da construção de jogos educativos na aprendizagem e atitudes dos alunos. Foram desenvolvidos, pelos discentes, diversos jogos educacionais, com vários conteúdos de diferentes disciplinas, tendo como base a teoria construtivista, que permite ao aluno construir o seu próprio conhecimento, através da procura de soluções para os problemas apresentados. Com este trabalho, os autores concluíram que os jogos desenvolvidos propiciaram aos alunos momentos de aprendizagem significativa, baseada na construção do seu próprio conhecimento, favorecendo um ambiente envolto em desafios motivadores, imaginação e satisfação em encontrar soluções para os problemas que foram surgindo. Assim, os alunos aprenderam os conteúdos de forma lúdica e dinâmica, ferramenta metodológica que foi muito bem aceite por professores e alunos.

Na mesma linha de pensamento, Victal e outros (2015), afirmam que a aprendizagem pode ser melhorada através da utilização de jogos digitais como instrumentos pedagógicos, no entanto, o próprio desenvolvimento dos jogos pelos aprendizes, poderá trazer-lhes novas habilidades e competências. 
Também Girard, Ecalle e Magnan (2013) fizeram um estudo de meta análise sobre a eficácia da utilização de jogos sérios e de jogos de vídeo, como ferramentas educacionais. Perante os vários artigos que analisaram, relacionados com esta temática, concluíram que existem algumas contradições em relação ao efeito destes jogos na educação, pelo que ainda são necessários mais estudos experimentais para que se possa garantir a eficácia destas ferramentas no processo de aprendizagem.

Tanto quanto é do nosso conhecimento, este trabalho diferencia-se dos demais realizados nesta área, pelo facto do jogo proposto neste artigo poder ser utilizado num formato totalmente físico, tal como é apresentado neste artigo, no entanto, pode ser facilmente adaptado num formato misto, isto é, o tabuleiro, os sólidos geométricos e o peão são apresentados na forma física, mas as questões do jogo poderão ser exibidas em formato digital, utilizando por exemplo, a ferramenta digital interativa, o kahoot. Com esta ferramenta, é possível introduzir novas perguntas, que são convertidas num jogo com pontuação, interação e ranking. Permite ao professor a elaboração de várias questões, de diferentes domínios da matemática, possibilita a avaliação do desempenho dos alunos, bem como a comparação dos resultados entre os intervenientes (Sande e Sande, 2018). Para a realização de uma atividade em que se utiliza o kahoot, os alunos necessitam de utilizar os seus telemóveis para visualizarem a questão e selecionarem a resposta.

\section{Método}

Nesta investigação pretende-se averiguar qual o impacto da construção de um jogo educativo de matemática em alunos do $3^{\circ}$ ciclo do ensino básico, com idades entre os $13 \mathrm{e}$ os 14 anos, na promoção do sucesso escolar e nas atitudes face à disciplina de matemática. A metodologia adotada baseia-se numa lógica de trabalho de natureza qualitativa e com recurso ao design de estudo de caso, sustentada em diversas técnicas de recolha de dados e produção de dados diversos. Trata-se de um estudo de caso misto pelo facto de existir uma combinação de instrumentos e técnicas, associadas aos estudos qualitativos e quantitativos. Neste caso, os dados foram recolhidos através da observação naturalista, aplicação de tarefas com o objetivo de construir o jogo "Trivial matemático" e aplicação de um inquérito por questionário aos alunos. Com esta investigação não se pretende fazer generalizações, pelo facto de o objeto de análise ser singular, o nosso foco centra-se na compreensão do fenómeno em estudo.

A opção metodológica de natureza qualitativa deveu-se a algumas características do fenómeno em estudo. Yin (2010) define estudo de caso como sendo uma abordagem empírica que investiga um fenómeno contemporâneo em profundidade, no seu contexto real; quando os limites entre determinados fenómenos e o seu contexto não são claramente evidentes e, no qual são usadas muitas fontes de dados.

Para a recolha de informação foram utilizados os seguintes instrumentos: tarefas para construir um jogo didático de matemática; uma grelha de observação comportamental e um inquérito por questionário aos alunos.

O jogo denominado "Trivial matemático" foi construído pelos alunos do $8^{\circ}$ ano de escolaridade do ensino básico de uma escola pública do norte de Portugal, seguindo os procedimentos de quatro tarefas. Foi utilizado material de baixo custo para a sua construção, fornecido pela docente de matemática da turma. Os materiais utilizados foram: quatro cartolinas com cores amarela, preta, vermelha e verde para construir o tabuleiro 
do jogo e o mostrador das questões, um dado com figuras geométricas, fichas com perguntas e sólidos geométricos, para serem usados como peões. Os alunos foram organizados em quatro grupos, constituídos por cinco elementos cada. Formaram-se grupos heterogéneos de forma propositada, para que os alunos com mais dificuldades não sentissem qualquer tipo de discriminação ou dificuldade na realização das tarefas. Para construir o jogo, foi necessário distribuir quatro tarefas por quatro grupos da turma, realizadas durante duas aulas de noventa minutos:

- Tarefa I: construção do tabuleiro do jogo, sendo composto por uma trilha geométrica constituída por 52 círculos.

- Tarefa II: construção dos cartões do jogo, compostos por 18 cartões com perguntas de escolha múltipla do domínio da Álgebra e ainda construção de um mostrador para colocar as questões.

- Tarefa III: construção do dado do jogo, cujos lados continham figuras geométricas regulares.

- Tarefa IV: construção dos sólidos geométricos, que serviram de peões do jogo, partindo das respetivas planificações.

De seguida, faz-se a descrição de cada uma das tarefas, iniciando com a tarefa I. Nesta tarefa, os alunos construíram o tabuleiro do jogo da seguinte forma: fizeram um círculo modelo com raio igual a $3 \mathrm{~cm}$, numa cartolina amarela; com o círculo modelo, construíram mais 50 círculos congruentes ao modelo de cor amarela e dois círculos numa cartolina de cor vermelha com as palavras "Saída" e "Chegada"; por fim, colocaram os 52 círculos numa folha de cartolina preta de forma a formar uma trilha geométrica não linear, com o objetivo de tornar o tabuleiro visualmente mais atraente. Podemos observar algumas etapas da construção do jogo na figura 1 .
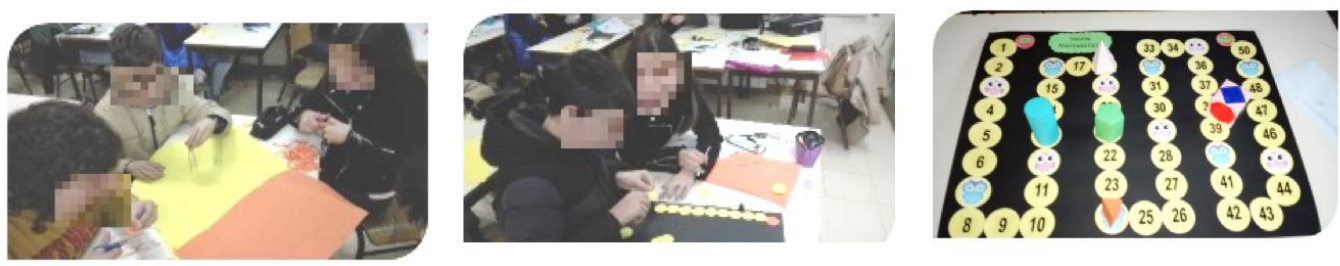

Figura 1. Construção do tabuleiro do jogo

Fonte: Elaborado pelos autores.

Na tarefa II foram construídos os cartões do jogo, com 18 questões de escolha múltipla, do domínio de "Álgebra", do $8 .^{\circ}$ ano de escolaridade, com quatro opções de resposta, em tamanho A4. Foi ainda construído um mostrador para colocar as questões. De seguida mostram-se algumas imagens da execução da tarefa II (figura 2). Na tarefa III os alunos construíram um dado com medidas de $5 \times 5 \times 5 \mathrm{~cm}$, e onde foram desenhadas em cada face do cubo as seguintes figuras geométricas regulares: triângulo; quadrado; pentágono; hexágono, heptágono e octógono. Estas figuras geométricas foram construídas a partir de circunferência com $3 \mathrm{~cm}$ de diâmetro. Na figura 3, encontram-se algumas imagens que elucidam a construção do cubo do jogo. 

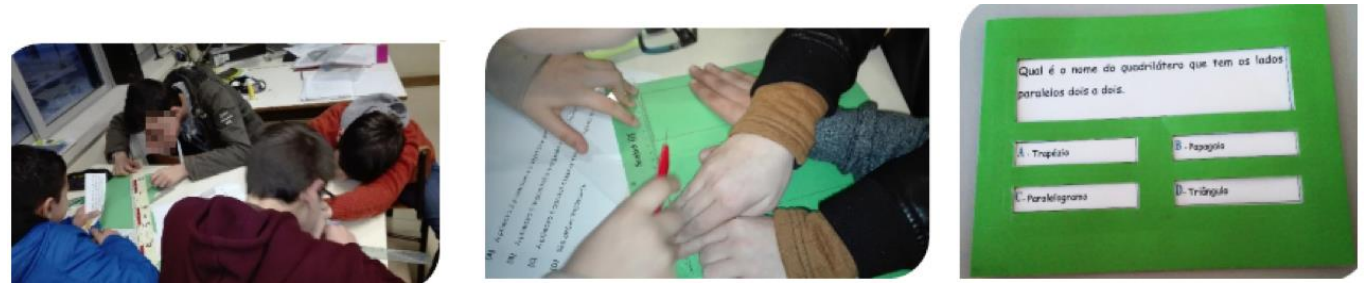

Figura 2. Construção dos cartões e do mostrador do jogo

Fonte: Elaborado pelos autores.
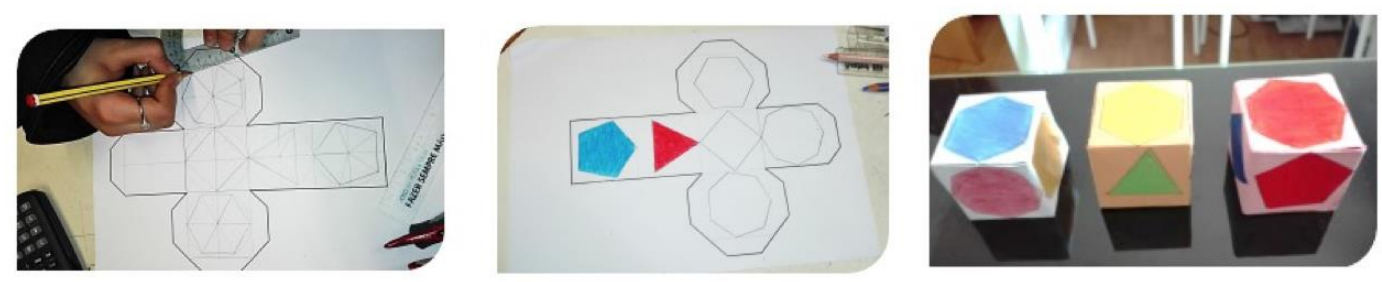

Figura 3. Construção de dados com figuras geométricas

Fonte: Elaborado pelos autores.

Finalmente, na tarefa IV foram construídos, a partir da respetiva planificação, os seguintes sólidos geométricos: prisma pentagonal; pirâmide quadrangular; prisma triangular, prisma quadrangular, cubo e cilindro. Os sólidos geométricos servem para serem usados como peões do jogo (figura 4).
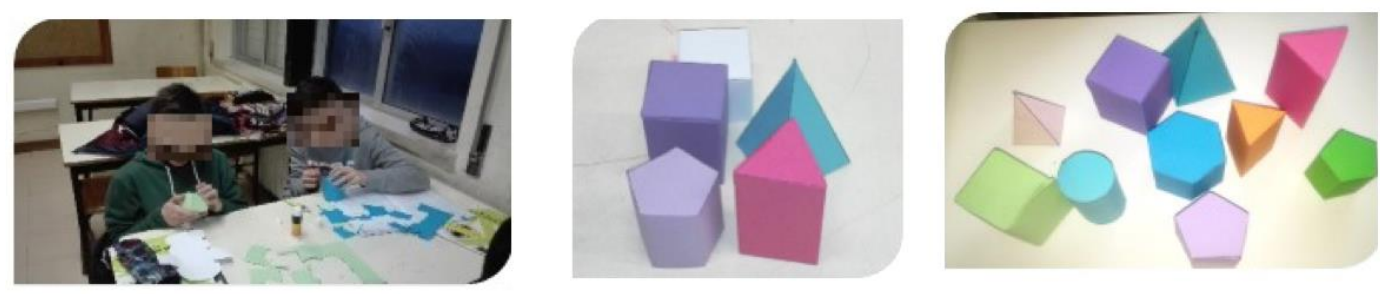

Figura 4. Construção de sólidos geométricos

Fonte: Elaborado pelos autores.

De seguida, procedeu-se à construção da ficha técnica do jogo, definiram-se o número de participantes e as regras do jogo. Nas regras do jogo, os autores fizeram um cruzamento entre dois jogos sobejamente conhecidos, o "Quem quer ser Milionário" e o jogo "Trivial". Do primeiro, foram utilizadas a possibilidade de usarem três tipos de ajudas ao longo do jogo: a ajuda do público, através de uma aplicação digital, onde o público poderá votar; a ajuda 50/50, onde serão eliminadas duas respostas erradas e a ajuda do manual, onde os jogadores poderão consultar a resposta correta, durante cinco minutos. Do jogo "Trivial" foi adaptada a ideia do tabuleiro e dos peões. Neste jogo devem participar grupos de duas a cinco pessoas e devem seguir as seguintes regras:

- Os cartões devem ser baralhados e colocados sobre a mesa com as perguntas viradas para baixo.

- Lançam o dado e o primeiro grupo a jogar é aquele que tirar o maior número de lados na figura geométrica. 
- O primeiro jogador lança o dado e desloca-se no tabuleiro tantas casas quantos forem os lados do polígono sorteado.

- Caso o jogador pare numa das casas marcadas com figuras, ele deve sortear um cartão. Se responder corretamente à pergunta, avança duas casas. Se errar, recua três casas. Caso não saiba a resposta pode usar três ajudas. Ao usar uma ajuda, o jogador só avança uma casa no tabuleiro. Estas ajudas podem ser usadas em separado ou as três para a mesma pergunta:

$\checkmark$ Ajuda do público, que podem votar online, durante dois minutos, através dos telemóveis, numa aplicação construída para esse efeito;

$\checkmark$ Ajuda do manual, durante cinco minutos, podem consultar os conteúdos/fórmulas/exercícios similares para responder à questão do jogo;

$\checkmark$ Ajuda 50/50, onde são eliminadas duas opções erradas.

- Depois de responderem à pergunta, o jogador coloca o cartão debaixo dos outros cartões.

- Ganha o jogo, quem conseguir alcançar a chegada em primeiro lugar.

A grelha de observação comportamental, adaptada de Pinheiro (2012), contém essencialmente aspetos relacionados com as atitudes dos quatro grupos de alunos, serviu para analisar as atitudes dos diferentes grupos na execução de cada uma das tarefas da construção do jogo educativo. Os resultados obtidos foram cruzados com as questões relativas às atitudes do inquérito por questionário, com o objetivo de ter mais informação relacionada com os comportamentos dos alunos, recolhida em mais do que uma fonte.

O inquérito por questionário foi constituído por 21 questões, sendo que foram privilegiadas as questões de resposta fechada, contendo apenas as três últimas de resposta aberta. As questões incidem sobre quatro aspetos fundamentais: a experiência que os alunos têm/ não têm na utilização e construção de jogos didáticos na matemática; as atitudes dos alunos; as aprendizagens na construção do jogo didático; vantagens/desvantagens e sugestões de melhoria do jogo. $\mathrm{O}$ aplicativo foi desenvolvido pelo professor investigador, antes da realização do estudo, e foi utilizado pelos alunos que desenvolveram o projeto, no sentido de fornecerem as respostas requeridas.

Os instrumentos de recolha de dados, designadamente as tarefas e a grelha de observação comportamental, foram aplicadas em ambiente de sala de aula, na presença da professora que levou a cabo a investigação. O inquérito por questionário foi aplicado aos alunos, via email, com recurso à ferramenta Google Docs, em ambiente fora da sala de aula. De realçar que, para perceberem as questões colocadas, houve por parte do professor investigador um enquadramento na sala de aula, relativamente aos domínios de matemática que são abordados durante todo o ano letivo, nomeadamente, Álgebra (ALG.); Funções, Sequências e Sucessões (FSS); Geometria e Medida (GM); Números e Operações (NO) e Organização e Tratamento de Dados (OTD). Foi ainda explicitado o domínio mais específico relacionado com o projeto em causa (GM). De referir ainda que, antes de enviar o questionário via email aos alunos, foi feito um pré-teste na aula, onde a professora distribuiu, em formato de papel, o referido inquérito por questionário, que os alunos preencheram e colocaram algumas questões relacionadas com as dúvidas que foram surgindo. Para o tratamento e análise dos resultados do inquérito por questionário, foi usado o software de análise estatística Statistical Package for the Social Sciences (SPSS, versão 25). 
Para a realização deste estudo, foram selecionados 20 alunos de uma turma do $8 .^{\circ}$ ano de escolaridade do ensino básico de um agrupamento de escolas do norte de Portugal e no ano letivo de 2017/2018 (quadro 1). A escolha dos alunos foi feita sob a forma de voluntariado, de entre os alunos da turma que quiseram participar neste estudo. A turma é constituída por sete alunas de género feminino (35\%) e treze do género masculino (65\%), inclui um aluno com necessidades educativas especiais, cujas medidas educativas são o apoio pedagógico personalizado e adequações no processo de avaliação. A faixa etária dos alunos encontra-se entre os 13 e os 14 anos. A média de idades dos 20 alunos é de 13,3 anos e o desvio-padrão é de 0,46, sendo que a média das idades dos rapazes é de 13,4 anos e das raparigas é de 13 anos. A moda e a mediana coincidem e correspondem à idade de 13 anos. Apresenta-se, de seguida, a caracterização da idade dos participantes, distribuídos por género.

Quadro 1. Idade dos participantes, por género

\begin{tabular}{lccc}
\hline & \multicolumn{2}{c}{ IDADE } & TotaL \\
\cline { 2 - 3 } & $\mathbf{1 3}$ & $\mathbf{1 4}$ & 13 \\
Masculino & 8 & 5 & 7 \\
Feminino & 7 & 0 & 20 \\
\hline Total & 15 & 5 & 20 \\
\hline
\end{tabular}

Fonte: Elaborado pelos autores.

\section{Resultados}

Para esta investigação é importante destacar que a grande maioria dos alunos (80\%) usou jogos didáticos na disciplina de matemática, entre uma ou duas vezes por período escolar, tal como podemos verificar no quadro 2 apresentada. Usualmente os professores utilizam aulas do final de período escolar para praticar jogos com os alunos e poderá ter sido nestas aulas que os alunos jogaram.

Quadro 2. Frequência de utilizações de jogos na aula de matemática

\begin{tabular}{lcc}
\hline & FREQUÊNCIA & PERCENTAGEM \\
\hline Não usei & 1 & 5 \\
Usei entre 1 ou duas vezes por período & 16 & 80 \\
Usei entre 1 ou 2 vezes por mês & 2 & 10 \\
Usei 1 a 2 vezes por semana & 1 & 5 \\
\hline Total & 20 & 100 \\
\hline
\end{tabular}

Fonte: Elaborado pelos autores.

É de salientar que a grande maioria dos alunos (70\%), não tem qualquer experiência na construção de jogos didáticos de matemática, tal como verificamos nos resultados apresentados no quadro 3. Pelos resultados obtidos relativos a esta questão, podemos verificar que esta é uma metodologia de ensino que não é utilizada com frequência pelos professores deste grupo de alunos.

Quadro 3. Experiência na construção de jogos didáticos de matemática

\begin{tabular}{lcc} 
& FREQUÊNCIA & PERCENTAGEM \\
\hline Não & 14 & 70 \\
Sim & 6 & 30 \\
\hline Total & 20 & 100 \\
\hline
\end{tabular}

Fonte: Elaborado pelos autores. 
Relativamente à opinião dos inquiridos sobre se os jogos de matemática são ou não o material mais adequado à aprendizagem desta disciplina, as respostas obtidas indicam que a maioria dos alunos discorda ou discorda totalmente (70\%), que a utilização de jogos de matemática não são o material didático mais adequado para utilizar na aprendizagem desta disciplina. No entanto, também temos $30 \%$ dos alunos que concordam ou concordam totalmente. Não nos podemos esquecer de que, para alguns alunos, os jogos são vistos como objetos de diversão e não como recursos didáticos (quadro 4).

Quadro 4. Opinião sobre se os jogos de matemática são o material mais adequado à aprendizagem na disciplina de matemática

\begin{tabular}{lcc}
\hline & FreQUÊNCIA & PERCENTAGEM \\
\hline Discordo totalmente & 5 & 25 \\
Discordo & 9 & 45 \\
Concordo & 5 & 25 \\
Concordo totalmente & 1 & 5 \\
\hline Total & 20 & 100 \\
\hline
\end{tabular}

Fonte: Elaborado pelos autores.

No que diz respeito à avaliação das atitudes dos alunos da turma, durante o processo de construção de um jogo educativo, foram realizadas quatro questões relativas ao grau de participação, grau de empenho, ao comportamento e à comunicação entre alunos e professora e as respostas foram as seguintes: $65 \%$ dos alunos classificam o grau de motivação na elaboração de jogos didáticos de matemática como "Motivado"; 30\% "Muito motivado" e 5\% "Pouco motivado"; 80\% dos alunos classificam de "Participativo" o grau de participação na construção de jogos didáticos de matemática e $20 \%$ responderam "Muito participativo"; $80 \%$ dos alunos classificou o seu grau de empenho nestas atividades com "Bom", $15 \%$ com "Muito bom" e com 5\% com "Mau"; o comportamento da turma nas aulas de construção de jogos didáticos foi classificado com "Bom" para $85 \%$ dos alunos, com "Mau" para 10\% e com "Não sei/não percebi" para 5\%; 80\% dos alunos "Concorda" que a construção de jogos didáticos de matemática favoreceu a comunicação entre alunos e professora e $20 \%$ responderam "Concordo totalmente". Relativamente às aprendizagens de matemática, na construção do jogo didático, os resultados são apresentados o quadro 5 .

Quadro 5. Aprendizagens de conceitos de matemática na construção do jogo didáticos

\begin{tabular}{lcc}
\hline & FrEQUÊNCIA & PERCENTAGEM \\
\hline Concordo & 12 & 60 \\
Concordo totalmente & 8 & 40 \\
\hline Total & 20 & 100 \\
\hline
\end{tabular}

Fonte: Elaborado pelos autores.

Nesta questão os alunos apenas responderam em duas opções, das cinco disponíveis, $60 \%$ dos alunos considera que "Concorda" que a construção do jogo didático ajudou a desenvolver conceitos de matemática e 40\% "Concorda totalmente". Nestas respostas torna-se evidente que, para estes alunos, a metodologia da utilização de jogos didáticos de matemática, promove o desenvolvimento de conceitos de matemática inerente à construção do jogo. 
Relativamente à questão "A participação na construção de jogos didáticos de matemática ajudou-te a superar melhor as dificuldades nos conteúdos de geometria", 80\% dos alunos considera que "Concorda" que a construção de jogos didáticos de matemática ajudou a superar melhor as dificuldades em geometria, 15\% "Concorda totalmente” e 5\% respondeu "Não sei/Não percebi”. As respostas dadas à questão "A construção do jogo didático de matemática promoveu a aprendizagem de conceitos de geometria”, 70\% respondeu "Concordo" e 30\% "Concordo totalmente". No que diz respeito à questão "Os jogos didáticos facilitam a transmissão de conceitos de matemática”, 80\% respondeu "Concordo" e 20\% "Concordo totalmente". No que respeita à questão "A participação ativa na construção de jogos didáticos de matemática contribui para o sucesso escolar dos alunos", $85 \%$ respondeu "Concordo" e 15\% "Concordo totalmente".

Pelos resultados obtidos nas questões atrás referidas e pelos dados recolhidos, através da observação naturalista, durante a construção do jogo educativo, registados numa grelha de observação comportamental, podemos inferir que, a construção do jogo educativo, promoveu a motivação destes alunos e consequentemente, as aprendizagens de conceitos de geometria envolvidos na sua construção. Relativamente à questão sobre a relação entre a construção e utilização de jogos didáticos de matemática e a concretização de conceitos abstratos de matemática (quadro 6).

Quadro 6. Contribuição dos jogos didáticos para a concretização de conceitos abstratos de matemática

\begin{tabular}{lcc}
\hline & FreQuênCIA & PERCENTAGEM \\
\hline Discordo & 1 & 5 \\
Concordo & 16 & 80 \\
Concordo totalmente & 3 & 15 \\
\hline Total & 20 & 100 \\
\hline
\end{tabular}

Fonte: Elaborado pelos autores.

A maioria dos alunos (95\%) considera que a utilização de jogos didáticos contribui para concretizar os conceitos mais abstratos de matemática. Seguem-se os resultados relativos à questão que se encontra descrita no quadro7.

Nas respostas dadas na questão referida no quadro 7, a maior parte dos alunos respondeu que o domínio “Geometria e Medida” seria o mais adequado para a utilização de jogos didáticos, esta resposta poderia ter sido influenciada pelo facto dos alunos trabalharem conceitos deste domínio para a construção deste jogo em particular. No entanto, nesta questão, todas as opções de resposta foram contempladas, o que poderá significar que, uma vez que não têm grande experiência na construção de jogos didáticos, os alunos não conseguem perceber qual o domínio que poderá beneficiar mais com a utilização desta metodologia ou ainda que todos os domínios poderão ser enriquecidos com a utilização de jogos didáticos.

No que diz respeito ao grau de importância da construção de jogos didáticos para a aprendizagem de matemática, as respostas obtidas são apresentadas no quadro 8. Os resultados obtidos na questão anterior sugerem que a construção de jogos educativos de matemática é uma metodologia que a ser utilizada na sala de aula, conta com uma boa aceitação por parte dos alunos no sentido de promover as aprendizagens matemáticas. 
Quadro 7. Domínios matemáticos escolhidos pelos alunos para explorar com jogos didáticos

\begin{tabular}{lcc}
\hline & FrEQUÊNCIA & PERCENTAGEM \\
\hline Álgebra & 3 & 15 \\
Geometria e Medida & 8 & 40 \\
Funções, Sequências e Sucessões & 5 & 25 \\
Organização e Tratamento de Dados & 2 & 10 \\
Números e Operações & 1 & 5 \\
Omisso: Não sei/Não percebi & 1 & 5 \\
\hline Total & 20 & 100 \\
\hline
\end{tabular}

Fonte: Elaborado pelos autores.

Quadro 8. Grau de importância da construção de jogos didáticos para a aprendizagem de matemática

\begin{tabular}{lcc}
\hline & FREQUENCIA & PERCENTAGEM \\
\hline Importante & 13 & 65 \\
Muito importante & 7 & 35 \\
\hline Total & 20 & 100 \\
\hline
\end{tabular}

Fonte: Elaborado pelos autores.

As três últimas questões são de resposta aberta, foram apresentadas várias respostas distintas, no entanto apresentamos apenas as duas respostas mais frequentes dadas pelos inquiridos relativas ao assunto de cada pergunta, os restantes resultados serão analisados num trabalho posterior. Assim sendo, no que diz respeito às vantagens da construção de jogos didáticos para a aprendizagem de matemática, as duas respostas mais frequentes foram: "Melhora/facilita a aprendizagem" (20\%) e "Melhorar a interação/ cooperação/entreajuda entre colegas” (20\%). Relativamente à questão sobre as desvantagens da construção de jogos didáticos para a aprendizagem de matemática, as duas respostas mais frequentes foram: "Pode levar a um pior comportamento da turma" (30\%) e "Ocupa demasiado tempo das aulas/provoca atraso na matéria" (25\%). Na última questão, pediam-se sugestões de melhoria para o jogo educativo e as respostas mais frequentes foram: "Fazer mais vezes" (35\%); em segundo lugar ficaram empatadas três tipos de resposta: "Variar matérias" (15\%); "Fazer diferentes tipos de jogos" (15\%) e "Não há melhorias” (15\%).

\section{Discussão}

As opiniões recolhidas na literatura existente indicam que a utilização de jogos educativos, nas aulas de matemática facilitam a aquisição de conhecimentos, através da mediação do professor e que é um recurso educativo adequado para motivar os alunos e, consequentemente, contribui para o seu sucesso escolar, de acordo com trabalhos realizados por Kishimoto (1994), Moratori (2003), Ke e Grabowski (2007), Gonçalves (2011) e McLaren e outros (2017).

Neste estudo, concluímos que a utilização ou construção de jogos educativos para ensinar conteúdos de matemática é uma prática educativa pouco habitual nos docentes dos alunos sobre os quais incidiu este trabalho. Os alunos estão pouco habituados a utilizar ou construir jogos didáticos nas aulas de matemática. Verificámos também que a construção 
de jogos educativos de matemática é uma metodologia que pode ser utilizada na sala de aula e conta com uma boa aceitação por parte dos alunos, no sentido de promover as aprendizagens de matemática.

Os resultados obtidos no inquérito por questionário e as atitudes dos alunos, registadas numa grelha de observação comportamental, durante a realização do projeto, permitiramnos inferir que a participação no design e construção de jogos didáticos contribui para aumentar a motivação na aprendizagem de matemática, validando assim a primeira questão de investigação. Para além de motivar mais os alunos para esta disciplina, esta estratégia de ensino promove, no geral, atitudes mais positivas em relação à disciplina de matemática, nomeadamente, na participação, no empenho, no comportamento e na comunicação.

Por outro lado, com este projeto, recolhemos indícios que poderão levar-nos a concluir que o jogo educativo facilitou a aquisição de conceitos geométricos inerentes à construção do jogo, contribuindo para promover a aprendizagem de conceitos de matemática, através do envolvimento dos alunos na lógica do jogo, da concretização de figuras geométricas e de sólidos geométricos, e consequentemente, fomentou o pensamento matemático, validando assim a segunda questão de investigação.

No caso estudado promoveu na aprendizagem de conceitos de geometria, pois facilitou a transmissão desses conceitos através da sua concretização e do envolvimento dos alunos na logica do jogo, contribuindo para melhorar a aprendizagem de matemática e consequentemente o sucesso escolar dos alunos, validando assim a segunda questão de investigação.

Os resultados alcançados neste estudo estão em linha de convergência com investigações realizadas por Silva e Morais (2011), Ke (2014), Katmada, Mayridis e Tsiatsos (2014), Shimohara e Sobreira (2015) e Victal e outros (2015), que concluíram que a construção de jogos educativos contribui para o desenvolvimento das aprendizagens de matemática e melhora as atitudes dos alunos face a esta disciplina.

\section{Conclusões}

Como consequência deste estudo, consideramos que a opção por uma prática de ensino que utilize a construção de jogos educativos deverá ocupar um lugar de destaque no ensino da matemática, por se revelar uma estratégia motivadora que, associando a teoria à prática, contribui para o desenvolvimento integral do aluno, podendo ser um recurso eficaz e uma estratégia de combate ao insucesso escolar dos alunos nesta disciplina. Com a utilização desta estratégia de ensino, os alunos poderão praticar competências e habilidades de outras disciplinas, nomeadamente, as Tecnologias de Informação e Comunicação, a Educação Tecnológica, a Educação Visual, promovendo a interdisciplinaridade.

Como principais contributos, é de salientar o desenvolvimento de novas investigações acerca das aprendizagens através da criação de jogos educativos, com o intuito de contribuir para as investigações já existentes nesta área. Com apenas este estudo, não é possível fazer generalizações, no entanto, com a realização de mais investigações nesta temática, poderíamos comparar resultados e verificar se existiriam diferenças significativas. Por outro lado, este estudo de caso permitiu confirmar o aumento do interesse e da motivação dos alunos pela aprendizagem com recurso aos jogos matemáticos. 
Como limitação ao estudo, verificou-se o facto da amostra estudada ser muito reduzida, pelo que se sugere que em trabalhos futuros, se procure aumentar o tamanho da amostra. Com apenas este estudo, não é possível fazer generalizações, no entanto, com a realização de mais investigações nesta temática, poderíamos comparar resultados e verificar se existiriam diferenças significativas entre os diferentes estudos.

Como sugestão de melhoria do jogo criado em sala de aula, seria interessante oferecer cartões com valores que dependem do resultado que o jogador obteve no dado, tornando mais difícil decorar as respostas e obrigando o estudante a fazer cálculos sempre que precise de jogar.

Como trabalhos futuros, pretende-se criar um laboratório de matemática, onde os alunos poderão criar e utilizar jogos didáticos de matemática, utilizando software informático, para vários domínios, vários anos de escolaridade e em diferentes formatos. Pretende-se ainda utilizar uma plataforma digital, onde o professor poderá estar em contacto permanente com os alunos, introduzir novas questões nos jogos construídos, enviar exercícios para trabalhar em casa, através da utilização dessa plataforma, bem como controlar o desempenho dos alunos.

\section{Agradecimentos}

Este trabalho é financiado por Fundos Nacionais através da FCT-Fundação para a Ciência e a Tecnologia, I. P., no âmbito do Projeto UID/CED/00194/2013 e do Projeto $\mathrm{UID} / \mathrm{MAT} / 00013 / 2013$.

\section{Referências}

Baptista, P. e DGEEC. (2017). Resultados escolares por disciplina $3^{\circ}$ ciclo do ensino público. Ano letivo 2014/2015. Lisboa: Direção Geral de Estatísticas da Educação e Ciência.

Baptista, P. e DGEEC. (2018). Principais indicadores. Resultados escolares por disciplina $3^{\circ}$ ciclo do ensino público 2011/2012-2015/2016. Lisboa: Direção Geral de Estatísticas da Educação e Ciência.

Girard, C., Ecalle, J. e Magnan, A. (2013). Serious games as new educational tools: How effective are they? A meta-analysis of recent studies. Journal of Computer Assisted Learning, 29(3), 207219.

Godoy, C. L. S. e Menegazzi, M. O. (2011, outubro). Uso de jogos no ensino da matemática. Comunicação apresentada em XIV Salão Intermunicipal de pesquisa. Lutheran University of Brazil, Guaíba.

Gonçalves, P. A. D. S. (2011). Jogos digitais no ensino e aprendizagem da matemática: Efeitos sobre a motivação e o desempenho dos alunos (Tese de Doutoramento). Universidade do Algarve, Algarve.

Grübel, J. M. e Bez, M. R. (2006). Jogos educativos. Revista Novas Tecnologias na Educação, 4(2), $57-79$.

Katmada, A., Mavridis, A. e Tsiatsos, T. (2014). Implementing a game for supporting learning in mathematics. Electronic Journal of e-Learning, 12(3), 230-242. 
Ke, F. (2014). An implementation of design-based learning through creating educational computer games: A case study on mathematics learning during design and computing. Computers $\xi^{\circ}$ Education, 73, 26-39.

Ke, F. e Grabowski, B. (2007). Gameplaying for maths learning: Cooperative or not? British Journal of Educational Technology, 38(2), 249-259.

Kishimoto, T. M. (1994). O jogo e a educação infantil. Perspectiva, 12(22), 105-128.

McLaren, B. M., Adams, D. M., Mayer, R. E. e Forlizzi, J. (2017). A computer-based game that promotes mathematics learning more than a conventional approach. International Journal of Game-Based Learning, 7(1), 36-56.

Moratori, P. B. (2003). Por qué utilizar jogos educativos no processo de ensino aprendizagem. Rio de Janeiro: UFRJ.

Moreira, D. e Oliveira, I. (2004). O jogo e a matemática. Lisboa: Universidade Aberta.

Pinheiro, J. G. (2012). Sentir, pensar e agir na relação: Um programa de promoção de competências sociais aplicado a uma criança com Síndrome de Williams (Dissertação de Mestrado). Escola Superior de Educação, Castelo Branco.

Sande, D. e Sande, D. (2018). Uso do kahoot como ferramenta de avaliação e ensino-aprendizagem no ensino de microbiologia industrial. HOLOS, 12, 170-189.

Shimohara, C. e Sobreira, E. (2015). Criando jogos digitais para a aprendizagem de matemática no ensino fundamental I. Anais do Workshop de Informática na Escola, 21(1), 72-99.

Silva, I. D. O. e Morais, M. J. D. O. (2011). Desenvolvimento de jogos educacionais no apoio do processo de ensino-aprendizagem no ensino fundamental. HOLOS, 7, 15-27.

Silva, L. M. (2015). Ludicidade e matemática: Um novo olhar para aprendizagem. Psicologia \& Saberes, 4(5), 10-22.

Victal, E., Junior, H., Rios, P. e Menezes, C. (2015). Aprendendo sobre o uso de jogos digitais na educação. Anais do XXI Workshop de Informática na Escola, 21, 444-453.

Yin, R. K. (2010). Estudo de caso: Planejamento e métodos. Porto Alegre: Bookman editora.

Zeza, B., Fanizzi, C., Benediti, F. e Nunes, F. (2012). Unidade didática: $O$ uso do jogo no ensino da matemática. São Paulo: Universidade de São Paulo.

\section{Breve CV dos autores}

\section{Paula Sofia Nunes}

Mestre em Ensino da Matemática no 3. Ciclo do Ensino Básico e no Secundário, Universidade de Trás-os-Montes e Alto Douro (UTAD). Licenciatura em Matemática (Ensino de), Universidade de Trás-os Montes e Alto Douro; Curso de Formação Especializada: Educação Especial-Domínio Cognitivo e Motor, Escola Superior de Educação de Fafe; Doutoranda em Didática de Ciências e Tecnologia, na especialidade em Didática de Ciências Matemáticas, Universidade de Trás-os_Montes e Alto Douro. Professora do ensino básico (3. ${ }^{\circ}$ ciclo) e do secundário da disciplina de Matemática. Linhas investigadoras: Didática da matemática, jogos sérios, software educativo, recursos educativos, plataformas digitais. ORCID ID: https://orcid.org/o000-0002-3262-8180. Email: psofianunes1@gmail.com 


\section{Armando A. Soares}

Doutorado em Física pela Universidade de Universidade de Trás-os-Montes e Alto Douro (UTAD). Áreas de interesse: Dinâmica de Fluidos Computacional, Energias Renováveis e Ensino da Física. Docente no departamento de Física, da Universidade de Trás-os-Montes e Alto Douro (UTAD), na escola de Ciências e Tecnologia. Membro do Centro de Investigação em Energias Renováveis- INEGI, polo da UTAD. Membro colaborador do Laboratório de Didática de Ciências e Tecnologia da UTAD/CIDTFF. ORCID ID: https://orcid.org/o000-0003-1860-2432.Email: asoares@utad.pt

\section{Paula Catarino}

Doutora em Matemática, área de especialização em semigrupos - álgebra, doutoramento concluído na Universidade de Essex, Reino Unido. É docente no departamento de Matemática, da Escola de Ciências e Tecnologia, da Universidade de Trás-os-Montes e Alto Douro (UTAD), Vila Real, Portugal. É Membro colaborador do Laboratório de Didática de Ciências e Tecnologia da UTAD/CIDTFF, da Universidade de Aveiro e membro integrado do CMAT-UTAD, polo da UTAD do Centro de Investigação de Matemática CMAT, da Universidade do Minho, Braga, Portugal. ORCID ID: https://orcid.org/0000-0001-6917-5093. Email: pcatarin@utad.pt 